\title{
Tabellen- und Abbildungsverzeichnisse
}

\section{TABELLEN}

Tabelle 1: $\quad$ Die soziologische Arbeitsteilung nach Burawoy | 14

Tabelle 2: $\quad$ Funktion, Leistung und Reflexion als Relationierungsmodi der Funktionssysteme | 66

Tabelle 3: $\quad$ Unterschiede zwischen Selbstbeschreibungen und Boundary Work | 115

Tabelle 4: $\quad$ Ebenen des Sinngehalts in der dokumentarischen Methode | 139

Tabelle 5: $\quad$ Stufen der dokumentarischen Interpretation von Interviews | 144

Tabelle 6: $\quad$ Dimensionen eines integrativen Wissenschaftsbegriffs | 151

Tabelle 7: $\quad$ Analytische Ansätze der Bündelung soziologischen Gedankenguts | 158

Tabelle 8: $\quad$ Richtlinien der Interviewtranskription | 173

Tabelle 9: $\quad$ Prinzipien der Erzeugung epistemischer Autorität in der Soziologie | 266

Tabelle 10: $\quad$ Typen soziologischer Identitätskonstruktion | 273

Tabelle 11: $\quad$ Innovatoren und Bewahrer in der Soziologie | 279

\section{ABBILDUNGEN}

Abbildung 1: Die Doppelstruktur der Soziologie | 29

Abbildung 2: $\quad$ Strukturierungsmomente der Soziologie | 163

Abbildung 3: Theoretisches Sampling der Soziologie | 165

Abbildung 4: $\quad$ Triadische Struktur der Selbst- und Fremdbeschreibung der Soziologie | 256 
